\title{
Competitividade de Dois Genótipos de Milho (Zea mays) CoM Plantas Daninhas sob Diferentes Espaçamentos entre Fileiras ${ }^{1}$
}

\author{
Competitivity between Weeds and Two Corn (Zea mays) Genotypes Grown Under Different \\ Row Widths
}

BALBINOT JR., A.A. ${ }^{2}$ e FLECK, N.G. ${ }^{3}$

\begin{abstract}
RESUMO - As relações de competição entre culturas e plantas daninhas são influenciadas pelas características morfofisiológicas e pelo arranjo espacial das plantas cultivadas. O objetivo deste trabalho foi avaliar o efeito do espaçamento entre fileiras, em dois genótipos de milho, sobre a habilidade da cultura em competir com plantas daninhas. Foi conduzido um experimento em campo, em Canoinhas-SC. Os tratamentos foram dispostos segundo o delineamento experimental inteiramente casualizado, em esquema fatorial $(2 \times 4 \times 2)$, com quatro repetições. Dois genótipos de milho, com características morfológicas distintas, foram cultivados em quatro espaçamentos entre fileiras $(0,4 ; 0,6 ; 0,8$; e $1,0 \mathrm{~m})$, com e sem a presença de plantas daninhas. Determinaram-se a massa seca da parte aérea das plantas daninhas, as características de plantas de milho, a produtividade e os componentes da produtividade de grãos do milho. Para os dois genótipos, a redução do espaçamento entre fileiras diminuiu a massa produzida pelas plantas daninhas, porém o efeito desse fator foi mais intenso com o híbrido do que com a variedade. À medida que o espaçamento entre fileiras foi reduzido, houve aumento da produtividade de grãos do híbrido 'AS-1544', tanto na presença quanto na ausência de plantas daninhas; contudo, para a variedade 'Cateto' o aumento de produtividade ocorreu apenas na presença de plantas daninhas quando o espaçamento entre fileiras diminuiu.
\end{abstract}

Palavras-chave: interferência, habilidade competitiva, manejo cultural de plantas daninhas, arranjo espacial de plantas.

\begin{abstract}
Competition between crops and weeds is influenced by plant morphophysiological characteristics and plant spatial arrangement. A field experiment was carried out in Canoinhas-SC to evaluate the effect of row width and two corn genotypes on crop ability to compete against weeds. The treatments were arranged in a completely randomized design, using a factorial scheme (2x4x2), with four replicates. Two corn genotypes with distinct morphological characteristics were grown under four row widths $(0.4 ; 0.6 ; 0.8$; and $1.0 \mathrm{~m})$, with and without weeds. Weed shoot dry matter, corn traits, corn yield and grain yield components were determined. Weed dry matter decreased with reduced row width in both genotypes, though more intensely in the hybrid genotype than in the variety. Corn grain yield increased with row width reduction under both interference conditions for the hybrid 'AS-1544', but only under weed presence for the 'Cateto' variety when row width decreased.
\end{abstract}

Key words: interference, competitive ability, weed management, plant spatial arrangement.

Recebido para publicação em 24.8.2004 e na forma revisada em 5.9.2005.

Eng.-Agr., M.S., Pesquisador da Empresa de Pesquisa Agropecuária e Extensão Rural de Santa Catarina (Epagri) Estação Experimental de Canoinhas, BR 280, km 219, Caixa Postal 216, 89460-000 Canoinhas-SC, <balbinot@epagri.rct-sc.br>. ${ }^{3}$ Eng.-Agr., Ph.D., Professor da Faculdade de Agronomia da Universidade Federal do Rio Grande do Sul - UFRGS, Caixa Postal 15100, 91501-970 Porto Alegre-RS, Bolsista do CNPq. 


\section{INTRODUÇÃO}

O arranjo espacial das plantas cultivadas constitui-se em fator relevante na definição das relações de competição entre elas (Fischer \& Miles, 1973; Norris et al., 2001). Espaçamentos reduzidos entre fileiras de plantas de milho, em relação aos convencionalmente usados $(0,8$ a $0,9 \mathrm{~m})$, além de proporcionarem maior produtividade de grãos (Argenta et al., 2001), podem, simultaneamente, suprimir o crescimento de plantas daninhas. Por meio de modelos teóricos, Fischer \& Miles (1973) simularam os processos de interferência entre plantas daninhas e culturas. Esses modelos indicaram ser possivel influenciar o resultado final da competição a favor da cultura com a utilização de arranjos espaciais eqüidistantes, os quais podem ser obtidos pela redução do espaçamento entre fileiras.

A redução do espaçamento entre fileiras propicia aumento da interceptação de luz pelo dossel das plantas cultivadas. Assim, a cultura ocupa o espaço de forma acelerada, diminuindo a disponibilidade de recursos ao crescimento e desenvolvimento de plantas daninhas (Tharp \& Kells, 2001; Knezevic et al., 2003). A redução do espaçamento entre fileiras do milho de 76 para $38 \mathrm{~cm}$ diminuiu a massa produzida pelas espécies daninhas Chenopodium album e Amaranthus retroflexus em até $29 \%$, bem como a quantidade de diásporos produzida por estas (Begna et al., 2001). Em semeadura realizada no espaçamento de $38 \mathrm{~cm}$ entre fileiras do milho, o dossel da cultura ocupou as entrelinhas uma semana antes do que em semeadura realizada no espaçamento de $76 \mathrm{~cm}$ (Teasdale, 1995).

Enfatiza-se, por outro lado, que alguns estudos indicam que o arranjo espacial das plantas não interfere na competitividade da cultura. A redução do espaçamento entre fileiras de milho não influenciou a produtividade da cultura e as produções de massa e de diásporos por Abutilon theophrasti (Teasdale, 1998). Também em trigo, a produção de massa pelas plantas daninhas não foi afetada pelo espaçamento entre fileiras (Rasmussen, 2004).

O efeito do arranjo espacial de plantas sobre a competitividade das culturas é dependente de fatores como: espécie cultivada, características morfofisiológicas dos genótipos, espécies daninhas presentes na área e época relativa de sua emergência, além de condições ambientais, principalmente temperatura, radiação solar e regime pluvial. Semeaduras de milho realizadas sob condições de baixas temperaturas do ar e do solo e reduzida intensidade luminosa resultam em lento crescimento das plantas no início do ciclo de desenvolvimento. Por isso, nessa situação, o espaçamento entre fileiras exerce elevada importância na velocidade de ocupação do nicho pelas plantas de milho (Bullock et al., 1988) e, conseqüentemente, sobre a competitividade da cultura. Nesse sentido, torna-se necessário determinar a potencialidade do arranjo espacial de plantas de milho na redução dos prejuizos ocasionados por plantas daninhas.

É provável que o efeito do arranjo espacial de plantas de milho sobre sua competitividade seja dependente das características morfofisiológicas dos genótipos utilizados. Segundo Lindquist et al. (1998), genótipos de milho diferem em estatura de planta, indice de área foliar, ângulo das folhas e taxa de crescimento. Desse modo, genótipos de milho que apresentam diferentes características morfofisiológicas demonstram variação em habilidade competitiva com plantas daninhas (Begna et al., 2001). Na presença de plantas daninhas, genótipos de milho "modernos" apresentaram menores reduções em produção de massa em relação a genótipos "antigos" (Tollenaar et al., 1997). Além disso, genótipos "modernos" apresentaram maior eficiência na utilização de nitrogênio e luz; por isso, em geral, foram mais competitivos que os genótipos 'antigos' (Tollenaar et al., 1994). Por sua vez, genótipos 'antigos' possuem elevada estatura de plantas e alta velocidade de incremento do indice de área foliar até a fase de enchimento de grãos (Lindquist \& Mortensen, 1998), o que lhes confere maior habilidade em suprimir o crescimento de plantas daninhas.

As hipóteses deste trabalho foram de que a redução do espaçamento entre fileiras aumenta a habilidade da cultura do milho em competir com plantas daninhas e que o genótipo de milho com maior estatura de planta possui maior capacidade em suprimir o crescimento de plantas competidoras. O objetivo deste trabalho foi verificar o efeito de

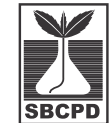


espaçamentos entre fileiras, em dois genótipos de milho, sobre a habilidade competitiva da cultura com plantas daninhas.

\section{MATERIAL E MÉTODOS}

Foi conduzido um experimento em Canoinhas-SC, durante a safra estival 2003/ 04, num solo classificado como Latossolo Vermelho distrófico (EMBRAPA, 1999). Os tratamentos foram dispostos em delineamento experimental inteiramente casualizado, em esquema fatorial $(2 \times 4 \times 2)$, com quatro repetições. Foram comparados dois genótipos de milho, o híbrido simples 'AS-1544' e a variedade de polinização aberta 'Cateto', os quais possuem características morfológicas distintas. Os genótipos foram dispostos em quatro espaçamentos entre fileiras $(0,4 ; 0,6 ; 0,8$; e $1,0 \mathrm{~m})$ e cultivados na presença ou ausência de plantas daninhas. As principais espécies daninhas presentes na área foram papuã (Brachiaria plantaginea - 190 plantas $\mathrm{m}^{-2}$ ) e leiteira (Euphorbia heterophylla-12 plantas $\mathrm{m}^{-2}$ ). Cada unidade experimental apresentou área total de $20 \mathrm{~m}^{2}(5 \times 4 \mathrm{~m})$ e área útil de $8 \mathrm{~m}^{2}$ $(4 \times 2 \mathrm{~m})$.

O preparo do solo foi realizado mecanicamente, por meio de escarificação e gradagem. As características físicas e químicas do solo foram: 5,3\% de matéria orgânica; $\mathrm{pH}_{\text {água }} \mathrm{de}$

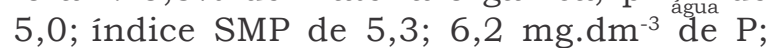
$0,25 \mathrm{cmol}_{\mathrm{dm}}^{-3}$ de $\mathrm{K} ; 0,08 \mathrm{cmol}_{\mathrm{c}} \mathrm{dm}^{-3} \mathrm{de} \mathrm{Al}$; e $16,2 \mathrm{cmol}_{\mathrm{c}}^{\mathrm{c}} \mathrm{dm}^{-3}$ de Ca+Mg. A semeadura do milho foi realizada manualmente no dia 3.11.2003. A população de plantas estabelecida para os dois genótipos foi de 55 mil plantas ha ${ }^{-1}$. O controle de plantas daninhas nas parcelas sem competição foi realizado com atrazine, em pós-emergência, na dose de $3,0 \mathrm{~kg} \mathrm{ha-1}$. As plantas remanescentes foram eliminadas por meio de capina.

Foram avaliadas a produção de massa pelas plantas daninhas nas parcelas infestadas, as características das plantas de milho (diâmetro do colmo e estatura final das plantas), os componentes da produtividade de grãos (número de espigas por planta, número de grãos por espiga e massa do grão) e a produtividade de grãos.

A produção de massa pelas plantas daninhas foi determinada aos 80 e 100 dias após a semeadura (DAS). A matéria da parte aérea das plantas daninhas, contida em amostra aleatória de $0,25 \mathrm{~m}^{2}$ por parcela, foi coletada e seca em estufa com circulação forçada de ar, à temperatura de $65^{\circ} \mathrm{C}$, até atingir peso constante, quando foi pesada. $\mathrm{O}$ diâmetro do colmo, determinado pela média de dez plantas amostradas ao acaso em cada parcela, foi medido com auxílio de um paquímetro no segundo entrenó da planta, contado a partir da superficie do solo. A estatura final das plantas de milho, constituida pelo comprimento da parte aérea das plantas, foi tomada desde o nível do solo até o ápice do pendão. O número de espigas por planta foi estimado pela média de dez plantas, amostradas em cada unidade experimental, nas quais se determinou o número de espigas formadas por planta. O número de grãos por espiga foi determinado em dez espigas por parcela amostradas ao acaso, nas quais foi contado o número de grãos formados por espiga. A massa de grãos foi determinada por meio da pesagem de 500 grãos por parcela, sendo os dados expressos em gramas por cem grãos, com correção da umidade para 13\%. A produtividade de grãos foi obtida pela colheita manual das espigas na área útil de cada unidade experimental $\left(8 \mathrm{~m}^{2}\right)$. Posteriormente, foram realizadas trilha e pesagem dos grãos. A produtividade foi corrigida para $13 \%$ de umidade, e os resultados, expressos em $\mathrm{kg}_{\text {ha }}{ }^{-1}$. Também se determinou a porcentagem de redução de produtividade de grãos decorrente da infestação com plantas daninhas.

Os dados coletados foram submetidos à análise de variância. Os dados de massa produzida pelas plantas daninhas e da produtividade de grãos foram submetidos à análise de regressão polinomial, testando-se os modelos linear e quadrático. As médias das demais variáveis foram comparadas pelo teste de Tukey. O nível de probabilidade do erro foi de $5 \%$ em ambas as análises.

\section{RESULTADOS E DISCUSSÃO}

Nas duas épocas de avaliação (80 e 100 DAS), a redução do espaçamento entre fileiras diminuiu a produção de massa aérea pelas plantas daninhas (Figura 1). No genótipo 'AS-1544', quando o espaçamento foi reduzido de 1 para 0,4 m, ocorreu redução de 46,1\% na

Planta Daninha, Viçosa-MG, v. 23, n. 3, p. 415-421, 2005 
massa de plantas daninhas aos 80 DAS. De maneira semelhante, Tharp \& Kells (2001) relataram redução de $28 \%$ na massa de Chenopodium album quando esta espécie competiu com milho semeado em espaçamento de $56 \mathrm{~cm}$, em relação ao de $76 \mathrm{~cm}$ entre fileiras. Isso ocorreu porque, em espaçamento reduzido, há menor competição entre as plantas de milho e maior velocidade de sombreamento das entrelinhas pela cultura, suprimindo as plantas competidoras.

No espaçamento de 0,4 m, o híbrido 'AS-1544' apresentou maior habilidade em suprimir o crescimento das plantas daninhas aos 80 DAS, em relação à variedade 'Cateto'
(Figura 1A). No entanto, nos espaçamentos de 0,8 e $1 \mathrm{~m}$, a variedade apresentou maior capacidade em suprimir o crescimento das plantas daninhas. Aos 100 DAS, por meio do teste 't', constatou-se que os coeficientes angulares das equações dos dois genótipos não diferiram significativamente; por isso, a massa de plantas daninhas é representada por apenas uma equação (média dos dois genótipos) (Figura 1B). Houve aumento dessa variável com o aumento do espaçamento entre fileiras do milho. Essa variação de massa produzida pelas plantas daninhas, em função do espaçamento, pode se refletir em diferentes produções de diásporos por estas plantas, os quais poderão emergir em cultivos subseqüentes.
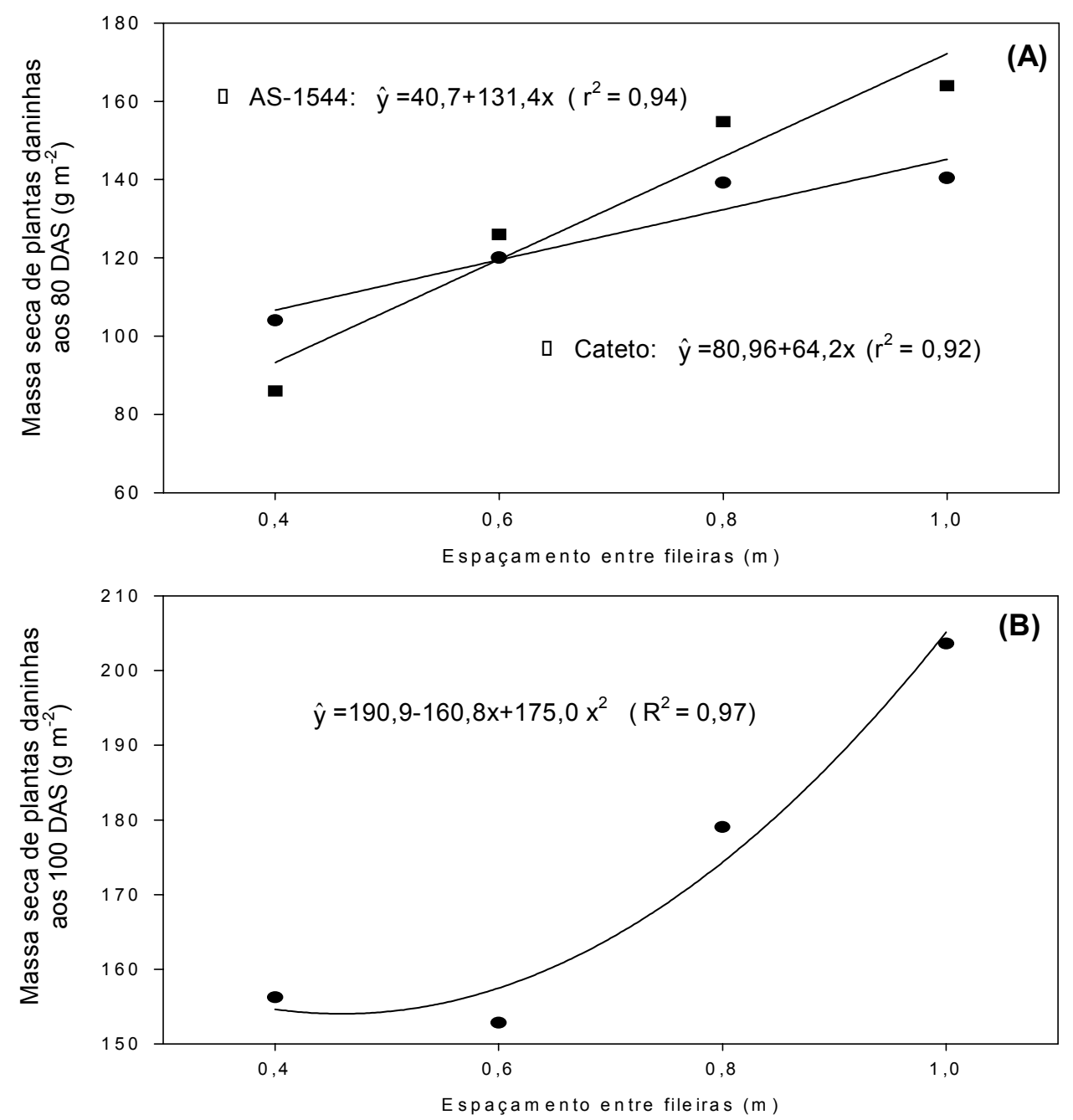

Figura 1 - Massa seca de plantas daninhas aos 80 dias após a semeadura (DAS) (A) e aos 100 DAS (B), influenciada por genótipos de milho e espaçamentos entre fileiras. Epagri, Canoinhas-SC, 2003/2004. 
Não houve efeito significativo do espaçamento entre fileiras sobre a estatura de planta e os componentes da produtividade de grãos. Essas variáveis foram influenciadas pelos genótipos e por condições de infestação pelas plantas daninhas (Tabela 1). O híbrido 'AS1544' apresentou maiores valores de diâmetro do colmo, número de espigas por planta, número de grãos por espiga e massa do grão, em relação à variedade 'Cateto' (Tabela 1). Todavia, o cultivar 'Cateto' apresentou estatura de planta $0,63 \mathrm{~m}$ superior à de 'AS-1544'. Na média dos dois genótipos, a presença de plantas daninhas reduziu o diâmetro do colmo, a estatura de planta e todos os componentes de rendimento de grãos (Tabela 1), com redução de $11 \%$ no número de grãos por espiga em decorrência da infestação por plantas daninhas.

O espaçamento entre fileiras afetou o diâmetro do colmo das plantas de milho (Tabela 1). Plantas de milho cultivadas em espaçamento de $0,4 \mathrm{~m}$ apresentaram maior diâmetro de colmo, comparativamente às cultivadas em espaçamento de $1,0 \mathrm{~m}$. Isso, provavelmente, decorre do fato de que, em arranjos mais eqüidistantes, há menor competição intraespecífica, favorecendo o crescimento das plantas de milho (Radosevich et al., 1997). Além disso, em menores espaçamentos, a cultura de milho consegue competir de maneira mais intensa com as plantas daninhas (Figura 1), obtendo condições mais apropriadas ao seu crescimento.

Houve aumento na produtividade de grãos com a redução do espaçamento entre fileiras, com exceção da variedade 'Cateto' cultivada sem competição com plantas daninhas (Figura $2 \mathrm{~A}, \mathrm{~B})$. Constatou-se que o aumento da produtividade de grãos, em função da diminuição do espaçamento, foi mais acentuado quando os genótipos foram cultivados na presença de plantas daninhas. Para o genótipo 'AS-1544', com a aproximação do espaçamento entre fileiras, houve diminuição linear na porcentagem de redução de produtividade decorrente da competição com plantas daninhas (Figura 2C). Ao contrário, para a variedade 'Cateto', a redução da produtividade foi diminuída com a redução do espaçamento até 0,6 m (ponto de mínimo da curva). Esse comportamento diferenciado entre genótipos provavelmente decorre de distintas características morfológicas apresentadas por eles. Enquanto a variedade 'Cateto' apresenta estatura de planta elevada (Tabela 1) e folhas mais decumbentes (arquitetura de planta "antiga"), o híbrido simples 'AS-1544' apresenta baixa estatura de planta e folhas eretas (arquitetura de planta "moderna").

Tabela 1 - Diâmetro do colmo, estatura de planta e componentes da produtividade de grãos de milho influenciados por genótipos, condições de infestação por plantas daninhas e espaçamentos entre fileiras. Epagri, Canoinhas-SC, 2003/2004

\begin{tabular}{|c|c|c|c|c|c|}
\hline Genótipo & $\begin{array}{l}\text { Diâmetro do } \\
\text { colmo }(\mathrm{cm})\end{array}$ & $\begin{array}{l}\text { Estatura de } \\
\text { planta }(\mathrm{m})\end{array}$ & $\begin{array}{c}\text { Número de } \\
\text { espigas por planta }\end{array}$ & $\begin{array}{c}\text { Número de grãos } \\
\text { por espiga }\end{array}$ & $\begin{array}{c}\text { Massa de } \\
100 \text { grãos }(\mathrm{g})\end{array}$ \\
\hline AS-1544 & $2,34 \mathrm{a}^{\frac{1}{\prime}}$ & $2,28 \mathrm{~b}$ & $0,97 \mathrm{a}$ & $407 \mathrm{a}$ & $31,6 \mathrm{a}$ \\
\hline Cateto & $2,27 \mathrm{~b}$ & $2,91 \mathrm{a}$ & $0,90 \mathrm{~b}$ & $193 \mathrm{~b}$ & $30,4 \mathrm{~b}$ \\
\hline \multicolumn{6}{|c|}{ Condições de infestação } \\
\hline $\begin{array}{l}\text { Sem ervas } \\
\text { Com ervas }\end{array}$ & $\begin{array}{l}2,43 \mathrm{a} \\
2,18 \mathrm{~b}\end{array}$ & $\begin{array}{l}2,66 \mathrm{a} \\
2,52 \mathrm{~b}\end{array}$ & $\begin{array}{l}0,95 \mathrm{a} \\
0,91 \mathrm{~b}\end{array}$ & $\begin{array}{l}318 \mathrm{a} \\
282 \mathrm{~b}\end{array}$ & $\begin{array}{l}31,7 \mathrm{a} \\
30,2 \mathrm{~b}\end{array}$ \\
\hline \multicolumn{6}{|l|}{$\begin{array}{c}\text { Espaçamentos entre } \\
\text { fileiras }\end{array}$} \\
\hline $\begin{array}{l}0,4 \mathrm{~m} \\
0,6 \mathrm{~m} \\
0,8 \mathrm{~m} \\
1,0 \mathrm{~m} \\
\end{array}$ & $\begin{array}{l}2,39 \mathrm{a} \\
2,37 \mathrm{ab} \\
2,25 \mathrm{ab} \\
2,23 \mathrm{~b}\end{array}$ & $\begin{array}{l}2,61 \mathrm{a} \\
2,59 \mathrm{a} \\
2,59 \mathrm{a} \\
2,57 \mathrm{a} \\
\end{array}$ & $\begin{array}{l}0,93 \mathrm{a} \\
0,93 \mathrm{a} \\
0,94 \mathrm{a} \\
0,92 \mathrm{a}\end{array}$ & $\begin{array}{l}313 \mathrm{a} \\
291 \mathrm{a} \\
291 \mathrm{a} \\
303 \mathrm{a} \\
\end{array}$ & $\begin{array}{l}31,2 \mathrm{a} \\
30,9 \mathrm{a} \\
30,8 \mathrm{a} \\
31,0 \mathrm{a}\end{array}$ \\
\hline Médias & 2,31 & 2,59 & 0,93 & 300 & 31,0 \\
\hline $\mathrm{CV}(\%)$ & 6,98 & 4,07 & 6,64 & 16,0 & 5,11 \\
\hline
\end{tabular}

${ }^{1 /}$ Médias seguidas da mesma letra, na coluna, não diferem entre si a 5\% de probabilidade pelo teste de Tukey. 

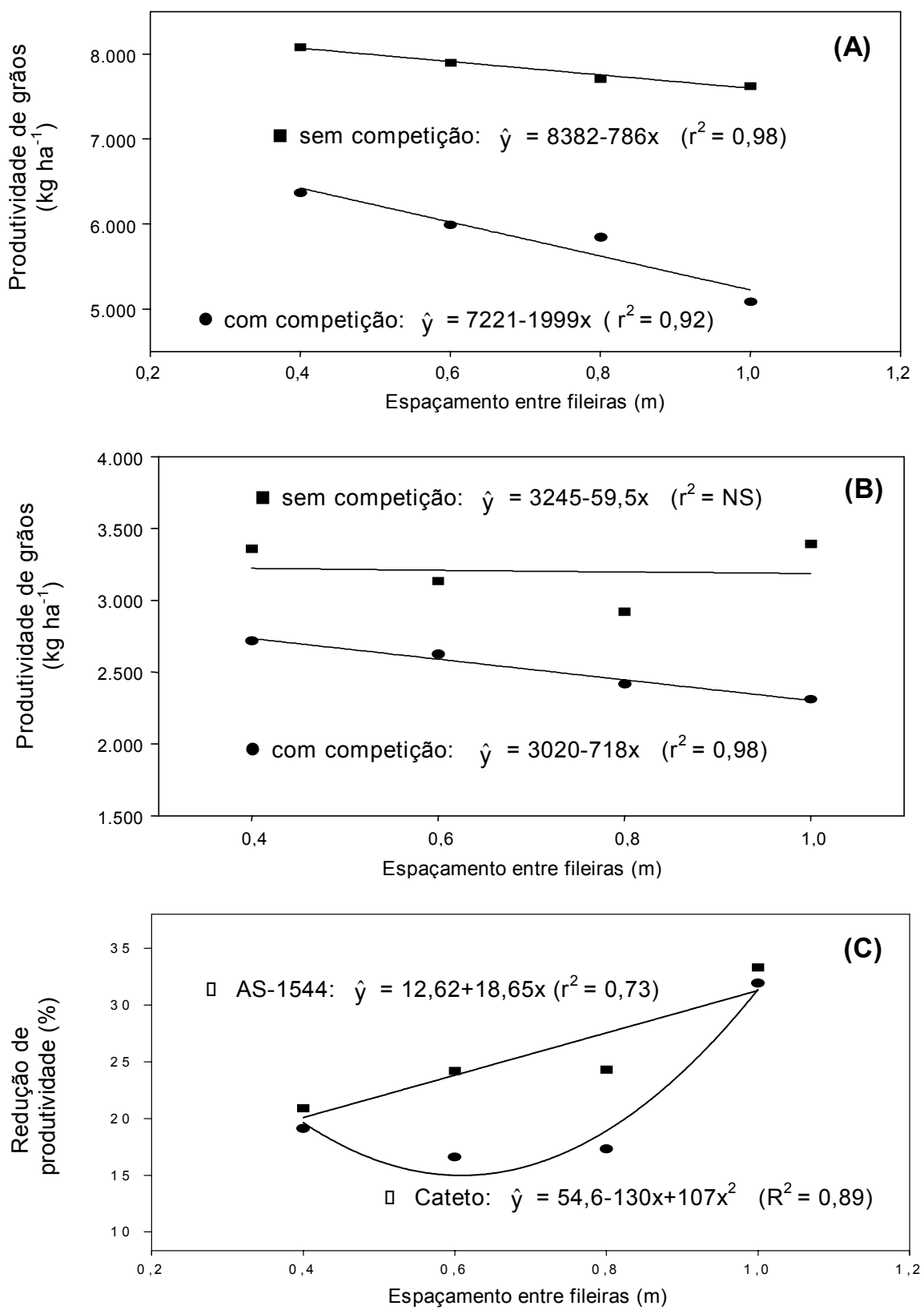

Figura 2 - Produtividade de grãos dos genótipos de milho 'AS-1544' (A) e 'Cateto' (B) e redução de produtividade (\%) (C), influenciadas pelos espaçamentos entre fileiras e por condições de competição com plantas daninhas. Epagri, Canoinhas-SC, $2003 / 2004$

De acordo com Teasdale (1995), mesmo que a redução do espaçamento entre fileiras de milho, em algumas situações, não resulte em aumento do rendimento de grãos, sua adoção pode se justificar pelo aumento da competitividade da cultura com plantas daninhas, devido à maior quantidade de luz que é interceptada pelo dossel da cultura. Assim, em milho, o uso de espaçamentos reduzidos constitui-se numa prática que pode auxiliar no manejo cultural de plantas daninhas, diminuindo a dependência do controle químico. Pesquisas têm demonstrado que a adoção de práticas de manejo que aumentem a competitividade da 
cultura, associadas a aplicações de herbicidas, pode resultar em melhor controle de plantas daninhas (Swanton \& Weise, 1991). A utilização de práticas de manejo que propiciem vantagem competitiva à cultura, como redução do espaçamento entre fileiras, permite diminuição na dose e no número de aplicações de herbicidas, reduzindo o custo de condução da lavoura e a contaminação do ambiente (Buhler et al., 1992). Em soja, Pires et al. (2001) verificaram que em espaçamento entre fileiras de $40 \mathrm{~cm}$ foi possivel reduzir a dose de herbicidas em até $50 \%$ sem afetar o controle de papuã (Brachiaria plantaginea), em relação ao espaçamento de $60 \mathrm{~cm}$. Um ponto importante, por outro lado, é que o uso de espaçamentos reduzidos em milho requer adaptações em máquinas, principalmente em semeadoras e colhedoras, o que pode dificultar a adoção dessa tecnologia, especialmente por agricultores que cultivam pequenas áreas.

O presente trabalho confirmou que a redução do espaçamento entre fileiras de milho é uma prática que aumenta a habilidade da cultura em competir com plantas daninhas, em especial em genótipo que apresenta arquitetura de planta "moderna".

\section{LITERATURA CITADA}

ARGENTA, G.; SILVA, P. R. F.; SANGOI, L. Arranjo de plantas em milho: análise do estado-da-arte. Ci. Rural, v. 31, n. 6 , p. 1075-1084, 2001.

BEGNA, S. H. et al. Morphology and yield response to weed pressure by corn hybrids differing in canopy architecture. Eur. J. Agron., v. 14, n. 4, p. 293-302, 2001.

BUHLER, D. D.; GUNSOLUS, J. L.; RALSTON, D. E. Integrated weed management techniques to reduce herbicide inputs. Agron. J., v. 84, n. 6, p. 973-978, 1992.

BULLOCK, D. G.; NIELSEN, R. L.; NYQUIST, W. E. A growth analysis comparison of corn grown in conventional and equidistant plant spacing. Crop Sci., v. 28, n. 2, p. 254-258, 1988.

EMPRESA BRASILEIRA DE PESQUISA AGROPECUÁRIA - EMBRAPA. Centro Nacional de Pesquisa de Solos. Sistema Brasileiro de Classificação de Solos. Brasília: EMBRAPA, 1999. 412 p.

FISCHER, R. A.; MILES, R. E. The role of spatial pattern in the competition between crop plants and weeds. A theoretical analysis. Math. Biosci., v. 18, p. 335-350, 1973.
KNEZEVIC, S. Z.; EVANS, S. P.; MAINZ, M. Row spacing influences the critical timing for weed removal in soybean (Glycine max). Weed Technol., v. 17, n. 4, p. 666-673, 2003.

LINDQUIST, J. L.; MORTENSEN, D. A. Tolerance and velvetleaf (Abutilon theophrasti) suppressive ability of two old and two modern corn (Zea mays) hybrids. Weed Sci., v. 46, n. 5 , p. $569-574,1998$.

LINDQUIST, J. L.; MORTENSEN, D. A.; JOHNSON, B. E. Mechanisms of corn tolerance and velvetleaf suppressive ability. Agron. J., v. 90, n. 6, p. 787-792, 1998.

NORRIS, R. F. et al. Spatial arrangement, density, and competition between barnyardgrass and tomato: II. Barnyardgrass growth and seed production. Weed Sci., v. 49, n. 1, p. $69-76,2001$.

PIRES, J. L. F. et al. Redução na dose do herbicida aplicado em pós-emergência associada a espaçamento reduzido da cultura de soja para controle de Brachiaria plantaginea. Planta Daninha, v. 19, n. 3, p. 337-343, 2001.

RADOSEVICH, S.; HOLT, J.; GHERSA, C. Weed ecology: implications for management. 2.ed. New York: Wiley, 1997. $588 \mathrm{p}$.

RASMUSSEN, I. A. The effect of sowing date, stale seedbed, row width and mechanical weed control on weeds and yields of organic winter wheat. Weed Res., v. 44, n. 1, p. 12-20, 2004.

SWANTON, C. J.; WEISE, S. F. Integrated weed management: the rationale and approach. Weed Technol., v. 5 , n. 3 , p. $657-663,1991$.

TEASDALE, J. R. Influence of narrow row/high corn population (Zea mays) on weed control and light transmittance. Weed Technol., v. 9, n. 1, p. 113-118, 1995.

TEASDALE, J. R. Influence of corn (Zea mays) population and row spacing on corn and velvetleaf (Abutilon theophrasti) yield. Weed Sci., v. 46, n. 4, p. 447-453, 1998.

THARP, B. E.; KELLS, J. J. Effect of glufosinate-resistant corn (Zea mays) population and row spacing on light interception, corn yield, and common lambsquarters (Chenopodium album) growth. Weed Technol., v. 15, n. 3, p. 413-418, 2001.

TOLLENAAR, M. et al. Effect of crop density on weed interference in maize. Agron. J., v. 86, n. 4, p. 591-595, 1994.

TOLLENAAR, M.; AGUILERA, A.; NISSANKA, S. P. Grain yield is reduced more by weed interference in an old than in a new maize hybrid. Agron. J., v. 89, n. 2, p. 239-246, 1997.

Planta Daninha, Viçosa-MG, v. 23, n. 3, p. 415-421, 2005 